\title{
Population Pharmacokinetic and Pharmacodynamic Modeling of Acetazolamide in Peritoneal Dialysis Patients and Healthy Volunteers
}

\author{
Corinne Seng Yue ${ }^{1}$, Huu H. Huynh ${ }^{2}$, Catherine Raymond ${ }^{2}$, Louise Charbonneau ${ }^{3}$, Louise Roy ${ }^{2}$ \\ ${ }^{1}$ Faculty of Pharmacy, University of Montreal; ${ }^{2}$ Department of Medicine and ${ }^{3}$ Department of Ophthalmology, CHUM- \\ Hôpital Saint-Luc, Canada.
}

Received, January 21, 2013; Revised March 27, 2013; Accepted, April 19, 2013; April 20, 2013.

\begin{abstract}
Purpose. To characterize the pharmacokinetics (PK) and pharmacodynamics (PD) of acetazolamide (ACTZ) in peritoneal dialysis patients, ACTZ $500 \mathrm{mg}$ was administered intravenously to 7 healthy subjects (HV) and 8 peritoneal dialysis patients (CAPD). Methods. Population PK/PD modeling was performed with ACTZ serum (total and unbound), urine and dialysate concentrations, intra-ocular pressure (IOP) and covariates. A multi-compartment PK model (accounting for non-linear protein binding) and an inhibitory Emax (maximal change in IOP) PD model were selected. Results. As expected, renal clearance (which almost equals total body clearance) was severely decreased in CAPD (1.2 vs $80.3 \mathrm{~L} / \mathrm{h}$ ) and the elimination half-life of total ACTZ was prolonged (20.6 vs 3.4 hours). The protein binding was significantly altered with a mean free fraction $4.2 \%$ in $\mathrm{HV}$ and $8.6 \%$ in CAPD. Moreover protein binding of ACTZ was concentration dependent in both HV and CAPD. Despite a higher free fraction of ACTZ, the Emax was lower in CAPD: $4.4 \pm 1.4$ vs $7.4 \pm 2.8 \mathrm{mmHg}$. Conclusion. Both PK and PD are significantly altered in dialysis patients.
\end{abstract}

This article is open to POST-PUBLICATION REVIEW. Registered readers (see "For Readers") may comment by clicking on ABSTRACT on the issue's contents page.

\section{INTRODUCTION}

Acetazolamide (ACTZ) is a carbonic anhydrase (CA) inhibitor that is used as an adjunctive treatment for open-angle glaucoma or secondary glaucoma and post vitrectomy, but that is also indicated for short-term preoperative therapy in angle-closure glaucoma (1), conditions frequently encountered in dialysis patients. ACTZ is well absorbed through the gastrointestinal tract and is distributed in various tissues, including erythrocytes, kidneys, liver, muscles, eyes and the central nervous system (1). It is highly bound to albumin $(>90 \%)$ and is mainly excreted unchanged in the urine (filtration and proximal tubular secretion) (1-3). Although the pharmacokinetics (PK) of ACTZ has been described in healthy volunteers, glaucoma patients and those suffering from transient elevation in intraocular pressure (IOP) (2, 4-6), little has been published about ACTZ PK in dialyzed patients besides a handful of case reports (7-10); from these we know that increased ACTZ serum concentrations may be associated with more side effects and that the dose should be adjusted accordingly in these patients (4,
9). This study was therefore conducted to better understand ACTZ PK and pharmacodynamics (PD) in this special population, comparing peritoneal dialysis patients and $\mathrm{HV}$, and investigating the impact of covariates on PK/PD.

\section{METHODS}

\section{Study design}

Eight patients with chronic renal failure treated with continuous ambulatory peritoneal dialysis (CAPD) and seven healthy volunteers (HV) participated in the protocol (approved by the hospital's local Ethics Committee) after providing informed consent. HV were recruited if their renal function was normal (serum creatinine and estimated creatinine clearance).

Corresponding Author: Louise Roy, M.D. Department of Medicine, Centre Hospitalier de l'Université de Montréal - Hôpital Saint-Luc, 1058 Saint-Denis, Montréal, Québec, Canada, Email : louise.roy@umontreal.ca 
All participants had a baseline ophthalmologic examination with IOP measurement. Exclusion criteria were IOP $>20 \mathrm{~mm} \mathrm{Hg}$, hemoglobin $<70$ $\mathrm{g} / \mathrm{L}$, serum bicarbonate $<20 \mathrm{~mm} / \mathrm{L}$, allergy to sulfa or local anesthetics, or regular administration of beta-blockers or corticosteroids.

After an 8 hour fast, all participants received ACTZ 500 mg (Novopharm, Montréal, Canada) intravenously over 2 minutes; breakfast was allowed one hour later. Serum urea, creatinine, glucose, electrolytes, $\mathrm{CO}_{2}$ albumin, protein and complete blood count were measured using standard techniques. Heparinized blood samples were obtained before $(0)$ and at $0.0833,0.167,0.25$, $0.5,0.75,1,1.5,2,3,4,6$ hours after dosing. Dialysate and urine (if possible for patients) were collected over the next 24 hours. Samples were centrifuged and stored at $-70^{\circ} \mathrm{C}$ until analysed.

IOP was measured with the Schiotz tonometer before (0) and 0.5, 1, 2, 4 and 8 hours after dosing. Each measurement was performed by the same person after a 5-minute rest in the supine position and local anesthesia with Alcaine $0.5 \%$ (proparacaïne).

\section{Determination of ACTZ in plasma, urine and dialysate}

The standard solution was ACTZ dissolved in methanol and the internal standard was sulfadiazine dissolved in methanol. As described by Chapron et al (11), ACTZ was measured with HPLC on a column $\mu$ Bondapak $\mathrm{C}_{18}(3.9 \times 300 \mathrm{~mm})$, with a flow rate set at $2.5 \mathrm{ml} / \mathrm{min}$. The mobile phase was made of acetate buffer, methanol and acetonitrile (95:2:3). The extraction was done with ammonium sulfamate and ethyl acetate. The intra-assay and inter-assay coefficient of variation $(\mathrm{CV} \%)$ for $\mathrm{ACTZ}$ serum concentrations of $10-100 \mu \mathrm{g} / \mathrm{ml}$ were $2.6-5.2 \%$ and $2.8-6.3 \%$, respectively.

\section{Plasma protein binding}

Plasma binding of ACTZ was measured by equilibrium dialysis at $37^{\circ} \mathrm{C}$ with a Teflon cell system (Spectrum) and a Spectapor 2 membrane (molecular weight 12,000-14,000). Each plasma sample was dialyzed against an equal volume of $0.067 \mathrm{M}$ phosphate buffer $\mathrm{pH} 7.4$ for 3 hours. The free fraction of ACTZ was calculated as: dialysate concentration/plasma concentration. The $\mathrm{CV} \%$ for the determination of $\mathrm{f}_{\mathrm{u}}$ was $2.8 \%$ at $20 \mathrm{ug} / \mathrm{ml}$ and $3.3 \%$ at $100 \mathrm{ug} / \mathrm{ml}$.
Free fraction $\left(f_{u}\right)$ was determined at different concentrations in spiked blank plasma: 10, 25, 50, 75 and $100 \mu \mathrm{g} / \mathrm{ml}$. After this experiment showed that $f_{u}$ was concentration dependent, protein binding was measured at 4 different concentrations, pooling the plasma of two consecutive (in time) samples, as there was a shortage of plasma samples. Hence total concentrations obtained after pooling were for $\mathrm{HV}$ $54,36,21$ and $14 \mu \mathrm{g} / \mathrm{ml}$; and for dialysis patients $44,41,32,23 \mu \mathrm{g} / \mathrm{ml}$.

Moreover, blood to plasma $(\mathrm{B} / \mathrm{P})$ ratio was measured in $3 \mathrm{HV}$ and $3 \mathrm{CAPD}$. Whole blood and plasma samples were spiked with ACTZ 10, 50 and $100 \mu \mathrm{g} / \mathrm{ml}$, and ACTZ concentration was determined after a 3-hour equilibration period.

\section{Pharmacokinetics and Pharmacodynamics}

Population $\mathrm{PK} / \mathrm{PD}$ analyses were conducted using NONMEM VI (12). Total ACTZ (ACTZ total $_{1}$ ) levels in plasma, urine and dialysate from all participants were simultaneously modeled, along with unbound ACTZ $\left(\mathrm{ACTZ}_{\text {free }}\right)$ concentrations in plasma. Standard model discrimination criteria (minimal objective function, residual figures, residual variability) were applied to select a structural PK model.

The impact of covariates on the base PK model was assessed graphically $(13,14)$. Forward stepwise addition followed by backward deletion was also used. After selecting the final PK model, individual PK parameters were fixed and used to determine the PD model, using the methods described for the PK model discrimination. Covariates that were tested for potential inclusion in both PK and PD models were age, weight and dialysis (categorical covariate).

\section{RESULTS}

Among the HV were 3 men and 4 women; there were 2 men and 6 women in the CAPD group. In HV vs CAPD: mean age was $29 \pm 7$ vs $54 \pm 6$, weight was $61 \pm 14 \mathrm{~kg}$ vs $68 \pm 16 \mathrm{~kg}$, baseline IOP ( IOP $\left._{\text {baseline }}\right)$ was $12.2 \pm 1.8 \mathrm{~mm} \mathrm{Hg}$ vs $15.6 \pm 3.4$ $\mathrm{mm} \mathrm{Hg}$, and serum albumin was $42 \pm 4 \mathrm{mg} / \mathrm{mL}$ vs $36 \pm 6 \mathrm{mg} / \mathrm{mL}$. The mean creatinine clearance in $\mathrm{HV}$ was $101 \pm 3 \mathrm{ml} / \mathrm{min}$ (estimated from Cockroft\&Gault nomogram).

In all, 179, 23 and 22 concentrations of $\mathrm{ACTZ}_{\text {total }}$ in plasma, urine and dialysate were simultaneously modeled. In addition, $60 \mathrm{ACTZ}_{\text {free }}$ 
plasma concentrations and 90 IOP measurements were analyzed. No adverse effects were observed in $\mathrm{HV}$ and CAPD during the study.

ACTZ PK in this population was best described by a multi-compartment model with central and peripheral compartments for $\mathrm{ACTZ}_{\text {total }}$ and a peripheral compartment for $\mathrm{ACTZ}_{\text {free }}$ (figure 1). Differential equations used to describe the model are presented in Appendix 1. Table 1 shows population parameter estimates for PK and PD of both healthy volunteers and CAPD patients. Figure 2 shows typical $\mathrm{ACTZ}_{\text {total }}$ serum and urinary ACTZ concentration vs time curves, with their corresponding predicted curves. Significant covariates included in the PK model were dialysis on renal clearance and age on distributional clearance (Q1). According to this model, the mean terminal elimination half-life of total ACTZ was 3.4 \pm 0.54 hours in HV and $20.6 \pm 10.5$ hours in CAPD patients. Appendix 2 provides examples of how covariates were coded in the model.

The $\%$ of unbound (fu) ACTZ was concentration-dependent: in $\mathrm{HV}$ it decreased from 5.3 to $3.3 \%$ over a range of 54 to $14 \mu \mathrm{m} / 1$, and from
14.3 to $8.0 \%$ over a range of 44 to $23 \mu \mathrm{m} / 1$ in CAPD. The relation between $\mathrm{ACTZ}_{\text {total }}$ and $\mathrm{ACTZ}_{\text {free }}$ was described by a Michaelis-Menten function. On average, the predicted $f_{u}$ of ACTZ with the model was greater in CAPD than in $\mathrm{HV}$ (8.6 vs $4.2 \%)$. Blood/plasma (B/P) ratio was higher in CAPD: for total ACTZ serum concentrations from 10 to $100 \mu \mathrm{g} / \mathrm{ml}$, it increased from 0.77 to 0.89 in $\mathrm{HV}$ and from 0.96 to 1.25 in CAPD.

The final PD model was an inhibitory Emax (maximal change in IOP) model (with $\mathrm{IOP}_{\text {baseline) }}$ that was directly related to $\mathrm{ACTZ}_{\text {free }}$ concentrations. Although indirect models linking IOP to ACTZ concentrations in the central compartment were also tested, the data was better explained by the direct model relating IOP to $\mathrm{ACTZ}_{\text {free }}$ concentrations. Significant covariates for the PD model were dialysis on $\mathrm{IOP}_{\text {baseline }}$ and Emax. $\mathrm{IOP}_{\text {baseline }}$ was $12.4 \pm 0.4$ in $\mathrm{HV}$ vs $15.5 \pm 1.6 \mathrm{mmHg}$ in $\mathrm{CAPD}$; Emax was $7.4 \pm 2.8$ in $\mathrm{HV}$ vs $4.4 \pm 1.4 \mathrm{mmHg}$ in CAPD. An average concentration-response curve for a healthy subject and dialysis patient is depicted in Figure 3.

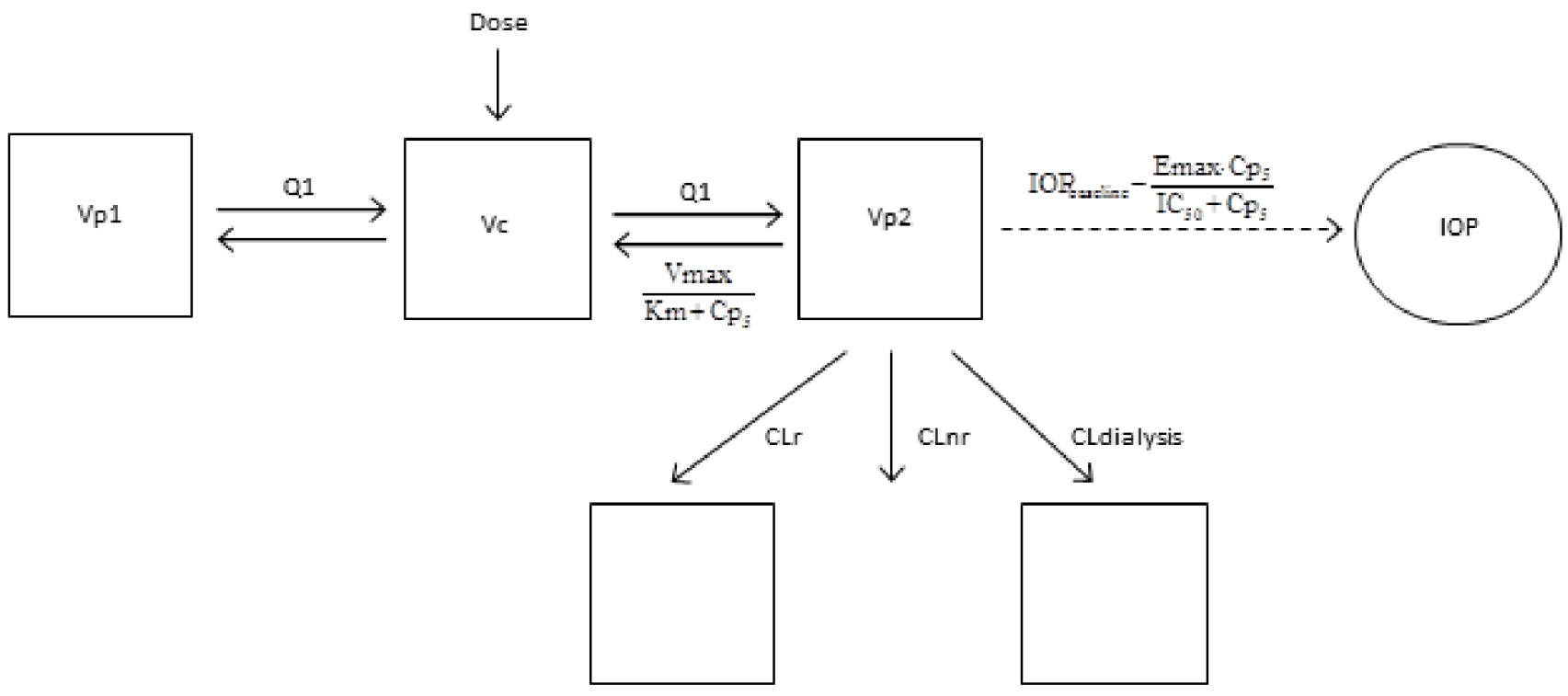

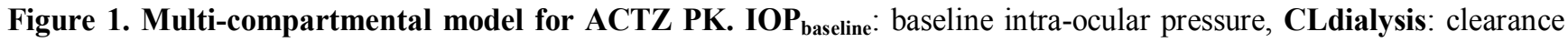
mediated by dialysis, CLnr: non-renal clearance, CLr: renal clearance, Cp5: concentration of unbound ACTZ, Emax: Maximal level of inhibition of IOP, IC $_{\mathbf{5 0}}$ : concentration of unbound ACTZ associated with 50\% of Emax, IOP: intra-ocular pressure, Km: unbound ACTZ concentration associated with 50\% of Vmax, Q1: distributional clearance between central and peripheral volumes for total ACTZ, Q2: distributional clearance between central and peripheral volumes for unbound ACTZ, Vc: central volume of distribution for total ACTZ, Vmax: maximal rate, Vp1: peripheral volume of distribution for total ACTZ, Vp2: volume of distribution for unbound ACTZ. 


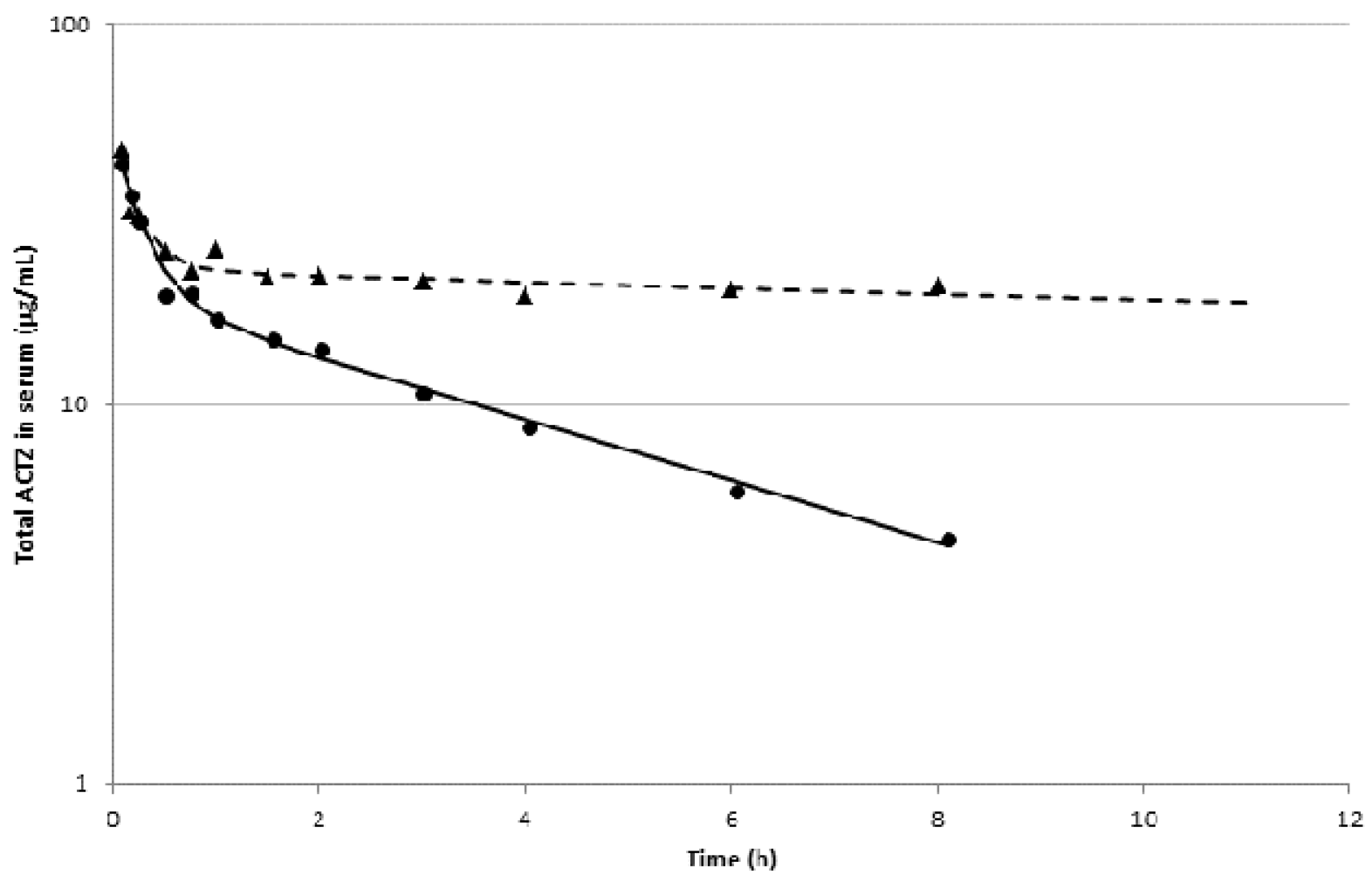

- Healthy observec Wealthy predicted $\triangle$ CAPD obsened - - CAPD predictec

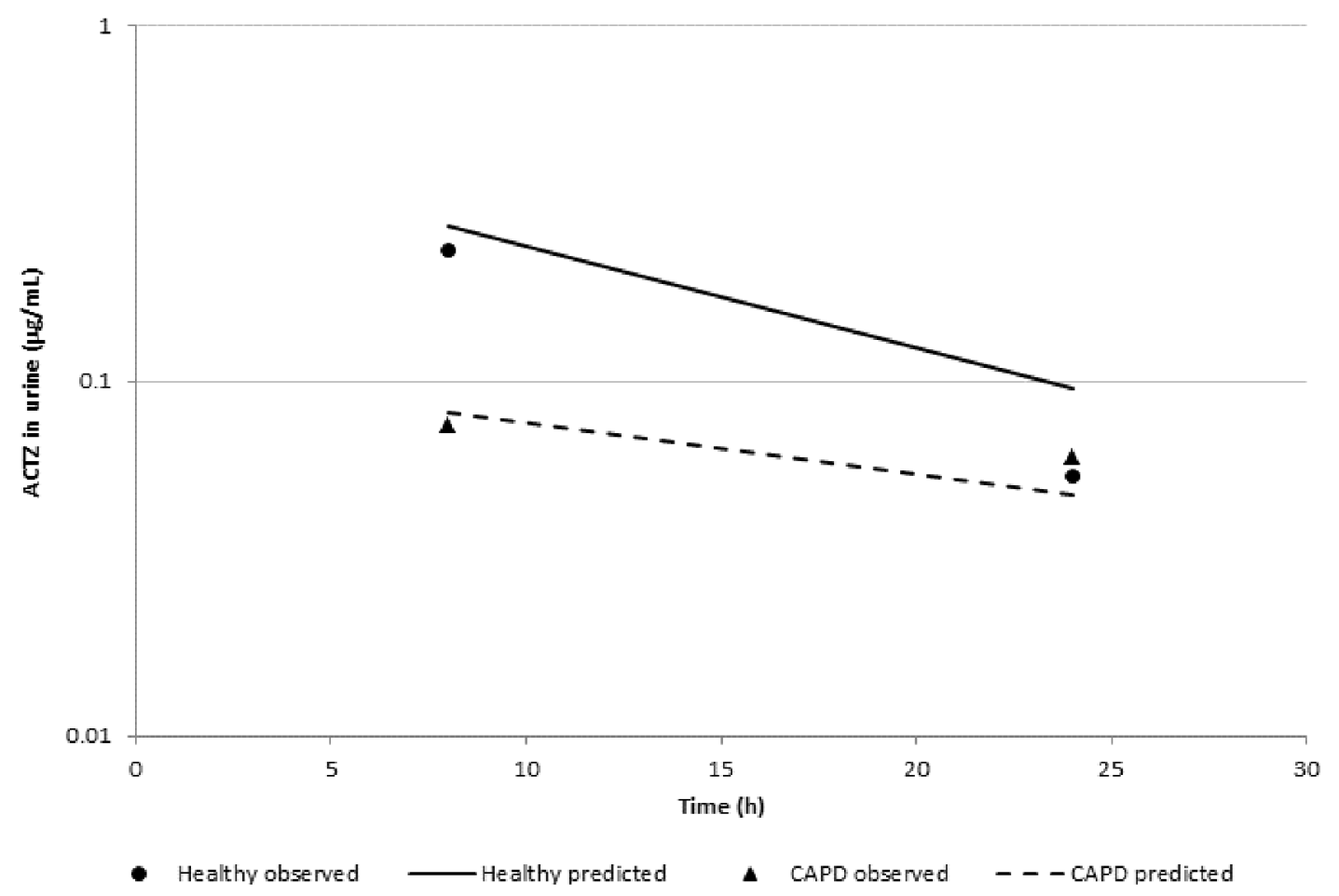

Figure 2. ACTZ $Z_{\text {total }}$ serum and urinary concentrations over time, observed and predicted, for Subjects \#1 (HV) and \#5 (CAPD) 


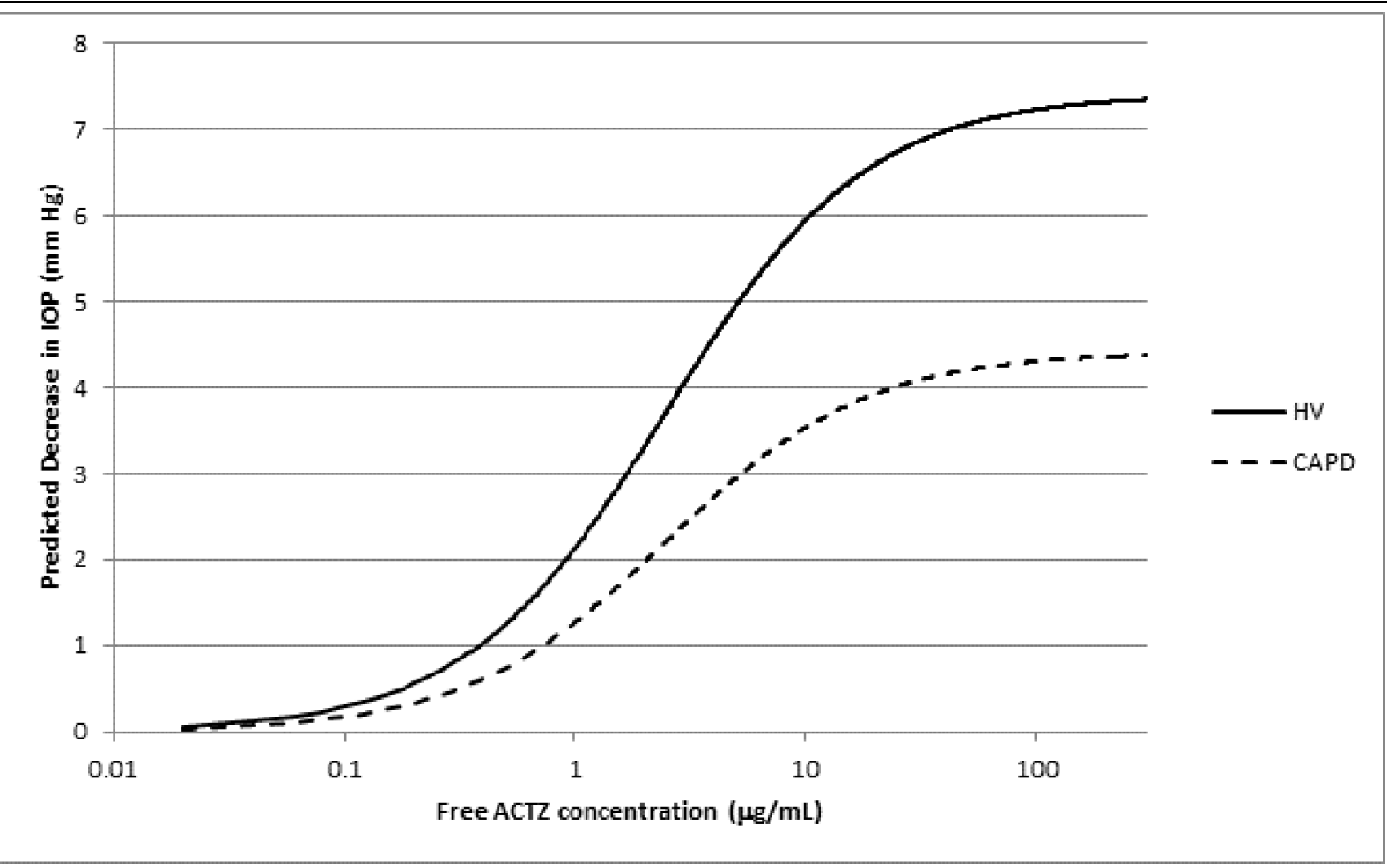

Figure 3. Predicted average $A C T Z_{\text {free }}$ concentration-response curve for $\mathrm{HV}$ subjects and CAPD patients

Residual variability (ranging from 10.5 to $39 \%$ ) associated with the final model was acceptable. This represents variability not explained by the model, including intra-individual variability, model misspecification or variability in the analytical assay. In addition, goodness-of-fit plots did not indicate any trends or biases in predictions.

Inter-individual variability was assumed to be centered around a mean value of zero with a variance of $\omega^{2}$. Intra-individual variability was modeled as a combination of additive and proportional error, except for ACTZ in urine and dialysate where the error model was simply proportional.

\section{DISCUSSION}

ACTZ PK in HV and glaucoma patients has been previously described $(2,4-7,15)$; our study further elucidates the $\mathrm{PK} / \mathrm{PD}$ relation in dialysis patients, using a population PK/PD approach. Although standard, noncompartmental analyses could have been used given the rich sampling scheme, the population $\mathrm{PK} / \mathrm{PD}$ approach was adopted to gain a more mechanistic understanding of the $\mathrm{PK} / \mathrm{PD}$ of
ACTZ in this population. In addition, the population approach has the potential to partition variability into inter-individual, intra-individual, inter-occasion and residual sources, as well as quantify the impact of covariates on variability (16). Thus, this approach was favored over the simpler noncompartmental approach.

The final PK/PD model was a multicompartment model describing the disposition of both $\mathrm{ACTZ} Z_{\text {total }}$ and $\mathrm{ACTZ}_{\text {free }}$, and the effects of the latter on IOP. The administration of ACTZ by the IV route allowed the model to accurately characterize the distribution phenomenon since it was not confounded with absorption processes. A key feature of this model is the non-linear function that links $\mathrm{ACTZ}_{\text {free }}$ to $\mathrm{ACTZ}_{\text {total. }}$ During the model discrimination process, linear functions were also investigated but the function that best described this transfer remained a saturable one, as observed by others (2). Gomolin and colleagues reported a linear relationship between total and $\mathrm{ACTZ}_{\text {free, }}$ however their $\mathrm{ACTZ}$ free concentrations varied from 6 to $10 \mathrm{mcg} / \mathrm{ml}$ (6), while they ranged from 0.38 to $12 \mathrm{mcg} / \mathrm{ml}$ in our study, allowing us to capture the non-linearity over a larger span of serum 
concentrations. Plasma drug binding to protein is generally a saturable process, depending on the dissociation constant, at higher concentrations (17), but sometimes it appears at therapeutic range concentrations $(2,17,18)$ as shown in our study.

The terminal elimination half-life for total ACTZ estimated by compartmental analysis was compared to parameters estimated by noncompartmental methods (for information purposes). Terminal elimination half-life for total ACTZ estimated by noncompartmental methods was around $3 \pm 0.6$ hours for healthy volunteers and $24 \pm 24$ hours for CAPD patients, which was similar to what was estimated by the model.

The $f_{u}$ remained greater in CAPD than in HV over the range of concentrations studied. This suggests that in this population, more $\mathrm{ACTZ}_{\text {free }}$ was available to penetrate other compartments, for instance erythrocytes, as witnessed by higher $\mathrm{B} / \mathrm{P}$ ratios. Indeed, severe renal failure alters protein binding, especially for acidic drugs binding to albumin (19). However, since our CAPD were generally older than the HV, this difference could partly be related to age. Actually, Chapron et al. (2) showed that age could be a factor influencing ACTZ distribution in plasma and erythrocytes; however the "age effect" $\left(60 \%\right.$ increase in $f_{u}$ in their elderly subjects) was much smaller than the "dialysis effect" $\left(105 \%\right.$ increase in $f_{u}$ in our CAPD mildly older patients). Our covariate analysis revealed that age influenced the transfer of $\mathrm{ACTZ}_{\text {total }}$ between the central and peripheral compartments as older subjects had a greater Q1. Hence, both age and renal function could play a role independently from each other in the alteration of distribution.

End-stage renal disease (ESRD) was the other significant covariate in our model that influenced renal clearance, $\mathrm{IOP}_{\text {baseline }}$ and Emax. $\mathrm{IOP}_{\text {baseline }}$ was higher in CAPD compared to HV, which could be due partly to the fact that this population was older. Indeed, IOP is known to increase slightly with age in certain populations (20). Despite having a greater $\mathrm{f}_{\mathrm{u}}$, CAPD had a mean Emax, that was almost 50\% lower compared to HV. This could be attributed to a possible competition with organic anions accumulating in renal dysfunction, for either uptake into the compartment (ciliary body) via an organic anion transporter (21), or for binding to the enzyme carbonic anhydrase (isoenzyme II) with an altered degree of inhibition of CA by ACTZ (17). The increased risk of toxicity and side effects of ACTZ in ESRD when given a standard dose (9) is therefore probably due more to a decreased clearance and consequently higher serum concentration, than solely to a greater $f_{u}$ that does not seem to enhance the PD response, at least at the ocular level. We observed a non-competitive pattern of concentration-response curve that could be explained by an irreversible modification of the enzyme in CAPD, as was described for the tertiary structure of albumin in uremic subjects (22).

Yano and colleagues (4) developed a PK/PD model for ACTZ in patients with transient IOP elevation and moderate to severe renal failure (estimated creatinine clearance $15-58 \mathrm{ml} / \mathrm{min}$; no dialysis patients). A one-compartment model with first-order absorption and an inhibitory Emax model were used to describe PK and PD, respectively. In their analysis, the only significant covariate for ACTZ total clearance was creatinine clearance, while they found no significant covariate effect on the PD parameters. The estimated Emax and $\mathrm{IC}_{50}$ in our HV were similar to the values they reported (7.2 $\mathrm{mm} \mathrm{Hg}$ and $1.64 \mathrm{mcg} / \mathrm{ml}$ ), which suggests that dialysis patients have a response that is distinct from non-dialysis patients, whether the $\mathrm{IOP}_{\text {baseline }}$ is normal or high. Furthermore, this suggests that the distinctive PD parameters that we estimated for our CAPD are not simply related to higher $\mathrm{IOP}_{\text {baseline }}$ values.

The results from our analysis were comparable to those published in case reports involving CAPD patients. The elimination half-life estimated for CAPD patients in our study (21 hours) was similar to the values of 29 hours (7) and 26 hours (9) observed by others. Thus, our results also demonstrated that CAPD patients had a decreased clearance of ACTZ. In addition, our analysis was able to identify which PK and PD parameters were different in CAPD patients in comparison with healthy volunteers.

Some of the limitations of our analysis include the small sample size and the small number of men $(n=5)$, which did not allow us to test sex as a covariate. The small sample size likely contributed to the elevated inter-subject variability associated with some PK/PD parameters. Furthermore, the CAPD were older than HV which could have some impact on the differences observed. In addition, ACTZ $f_{u}$ at different concentrations was obtained by pooling samples taken at different timepoints. 
Despite the limitations of this analysis, we have developed a model that describes ACTZ PK/PD in this special population, and revealed potential differences in comparison to HV. Our model suggests that not only are there differences in ACTZ PK in CAPD, but PD is altered as well: severely decreased total clearance (as it is eliminated almost solely by kidneys), decreased protein binding (which is saturable), and a reduced efficacy (decrease in Emax).

\section{REFERENCES}

1. AHFS Drug Information 2010.

2. Chapron DJ, Sweeney KR, Feig PU, Kramer PA. Influence of advanced age on the disposition of acetazolamide. $\mathrm{Br} \quad \mathrm{J}$ Clin Pharmacol1985 Mar;19(3):363-71.

3. Maren TH. Carbonic anhydrase: chemistry, physiology, and inhibition. Physiol Rev1967 Oct;47(4):595-781.

4. Yano I, Takayama A, Takano M, Inatani M, Tanihara H, Ogura Y, et al. Pharmacokinetics and pharmacodynamics of acetazolamide in patients with transient intraocular pressure elevation. Eur J Clin Pharmacol1998 Mar;54(1):63-8.

5. Sweeney KR, Chapron DJ, Antal EJ, Kramer PA. Differential effects of flurbiprofen and aspirin on acetazolamide disposition in humans. $\mathrm{Br} \mathrm{J}$ Clin Pharmacol1989 Jun;27(6):866-9.

6. Gomolin IH, Chapron DJ. Elucidating the relationship between acetazolamide plasma protein binding and renal clearance using an albumin infusion. J Clin Pharmacol1992 Nov;32(11):102832.

7. Schwenk MH, Blaustein DA, Wagner JD. The pharmacokinetics of acetazolamide during CAPD. Adv Perit Dial1994;10:44-6.

8. Schwenk MH, St Peter WL, Meese MG, Singhal PC. Acetazolamide toxicity and pharmacokinetics in patients receiving hemodialysis. Pharmacotherapy1995 Jul-Aug;15(4):522-7.

9. Roy LF, Dufresne LR, Legault L, Long H, Morin C. Acetazolamide in hemodialysis patients: a rational use after ocular surgery. Am J Kidney Dis1992 Dec;20(6):650-2.

10. De Marchi S, Cecchin E. Severe metabolic acidosis and disturbances of calcium metabolism induced by acetazolamide in patients on haemodialysis. Clin Sci (Lond)1990 Mar;78(3):295-302.

11. Chapron DJ, White LB. Determination of acetazolamide in biological fluids by reverse-phase high-performance liquid chromatography. J Pharm Sci1984 Jul;73(7):985-9.

12. Boeckmann AJ, Beal, S.L. \& Sheiner, L.B. NONMEM VI Users Guides. San Francisco, California2006.

13. Maitre PO, Buhrer M, Thomson D, Stanski DR. A three-step approach combining Bayesian regression and NONMEM population analysis: application to midazolam. J Pharmacokinet Biopharm1991 Aug;19(4):377-84.

14. Mandema JW, Verotta D, Sheiner LB. Building population pharmacokinetic--pharmacodynamic models. I. Models for covariate effects. J Pharmacokinet Biopharm1992 Oct;20(5):511-28.

15. Chapron DJ, Gomolin IH, Sweeney KR. Acetazolamide blood concentrations are excessive in the elderly: propensity for acidosis and relationship to renal function. J Clin Pharmacol1989 Apr;29(4):348-53.

16. Ette EI, Williams PJ. Population pharmacokinetics I: background, concepts, and models. Ann Pharmacother2004 Oct;38(10):1702-6.

17. Goodman\&Gilman's, editor. The Parmacological Basis of Therapeutics, 12th Edition 2011.

18. Gulati A, Boudinot FD, Gerk PM. Binding of lopinavir to human alpha1-acid glycoprotein and serum albumin. Drug Metab Dispos2009 Aug;37(8):1572-5.

19. Verbeeck RK, Musuamba FT. Pharmacokinetics and dosage adjustment in patients with renal dysfunction. Eur J Clin Pharmacol2009 Aug;65(8):757-73.

20. Wong TT, Wong TY, Foster PJ, Crowston JG, Fong $\mathrm{CW}$, Aung T. The relationship of intraocular pressure with age, systolic blood pressure, and central corneal thickness in an asian population. Invest Ophthalmol Vis Sci2009 Sep;50(9):4097-102.

21. Barar J, Javadzadeh AR, Omidi Y. Ocular novel drug delivery: impacts of membranes and barriers. Expert Opin Drug Deliv2008 May;5(5):567-81.

22. Koch-Weser J, Sellers EM. Drug therapy. Binding of drugs to serum albumin (second of two parts). N Engl J Med1976 Mar 4;294(10):526-31. 


\section{APPENDIX 1}

The PK of ACTZ was described by Equations 1 to 5, where PT is 0 for healthy volunteers and equal to 1 for CAPD. In these equations, A(1) represents the amount of ACTZ in the central compartment, $A(2)$ is the amount of ACTZ in the first peripheral compartment, A(3) is the amount collected in urine, A(4) is the amount collected in dialysate and $\mathrm{A}(5)$ is the amount in the second peripheral compartment (representing the unbound fraction of ACTZ).

Equation $1 \quad \frac{d A(1)}{d t}=-\left(\frac{Q 1+Q 2}{V 1}\right) \cdot A(1)+\frac{Q 1}{V 2} \cdot A(2)+\frac{V M \cdot(A(5) / V 3)}{K M+(A(5) / V 3)}$

Equation $2 \quad \frac{d A(2)}{d t}=\frac{Q 1}{V 1} \cdot A(1)+\frac{Q 1}{V 2} \cdot A(2)$

Equation $3 \quad \frac{d A(3)}{d t}=\frac{C L R}{V 3} \cdot A(5)$

Equation $4 \quad \frac{d A(4)}{d t}=P T \cdot \frac{C L D I}{V 3} \cdot A(5)$

Equation $5 \quad \frac{d A(5)}{d t}=\frac{Q 2}{V 1} \cdot A(1)-\frac{C L N R+C L R+P T \cdot C L D I}{V 3} \cdot A(5)-\frac{V M \cdot(A(5) / V 3)}{K M+(A(5) / V 3)}$

\section{APPENDIX 2}

Dialysis and age covariates were coded as per Equations 6 and 7, respectively.

Equation 6

$\theta_{\text {individual }}=\left[\theta_{\text {patient }} \cdot P T+\theta_{\text {healthy }} \cdot(1-P T)\right] \cdot e^{\eta}$

Equation 7

$$
\theta_{\text {individual }}=\theta_{\text {population }} \cdot\left(\frac{\text { Age }}{41.9}\right)^{\theta_{\text {age }}} \cdot e^{\eta}
$$


Table 1a. Population PK Parameter Estimates RSE: relative standard error calculated with respect to the mean parameter value, SE: Standard error

\begin{tabular}{|c|c|c|c|c|}
\hline Population Parameter & Parameter Description & Typical Value & SE & RSE\% \\
\hline \multicolumn{5}{|l|}{ Population Mean } \\
\hline CLnr $(\mathrm{L} / \mathrm{h})$ & Non-renal clearance & 1.53 & 0.69 & 44.9 \\
\hline $\mathrm{Vc}(\mathrm{L})$ & Central volume of distribution & 5.77 & 0.79 & 13.7 \\
\hline Q1 (L/h) & Distributional clearance between central and peripheral volumes for total ACTZ & 10.2 & 1.9 & 18.6 \\
\hline Exponent age & Exponent describing the effect of age on Q1 & 1.08 & 0.46 & 42.5 \\
\hline Vp1 (L) & Peripheral volume of distribution & 6.46 & 0.87 & 13.5 \\
\hline $\operatorname{CLr}(\mathrm{L} / \mathrm{h})$ & Renal clearance & & & \\
\hline Healthy & Renal clearance in healthy subjects & 80.3 & 8.7 & 10.8 \\
\hline Dialysis patient & Renal clearance in dialysis patients & 1.2 & 0.9 & 72.8 \\
\hline CLdialysis $(\mathrm{L} / \mathrm{h})$ & Clearance mediated by dialysis & 1.65 & 0.26 & 15.8 \\
\hline $\mathrm{Q} 2(\mathrm{~L} / \mathrm{h})$ & Distributional clearance between central and peripheral volumes for unbound ACTZ & 7.97 & 0.69 & 8.7 \\
\hline $\mathrm{Vp} 2(\mathrm{~L})$ & Volume of distribution for unbound ACTZ & 6.14 & 1.33 & 21.7 \\
\hline $\operatorname{Vmax}(\mathrm{mg} / \mathrm{h})$ & Maximal rate of transfer between compartments & 1510 & 123 & 8.1 \\
\hline $\mathrm{Km}(\mathrm{mg} / \mathrm{L})$ & Unbound ACTZ concentration associated with $50 \%$ of $\mathrm{Vmax}$ & 12.4 & 2.8 & 22.3 \\
\hline \multicolumn{5}{|l|}{ Inter-subject variability } \\
\hline $\mathrm{CLnr}(\mathrm{L} / \mathrm{h})$ & Non-renal clearance & $0.425(72.8 \%)$ & 0.648 & 152.5 \\
\hline $\mathrm{Vc}(\mathrm{L})$ & Central volume of distribution & $0.225(50.2 \%)$ & 0.127 & 56.4 \\
\hline $\mathrm{Q} 1(\mathrm{~L} / \mathrm{h})$ & Distributional clearance between central and peripheral volumes for total ACTZ & $0.234(51.3 \%)$ & 0.123 & 52.6 \\
\hline $\mathrm{Vp} 1(\mathrm{~L})$ & Peripheral volume of distribution & $0.209(48.2 \%)$ & 0.093 & 44.4 \\
\hline $\operatorname{CLr}(\mathrm{L} / \mathrm{h})$ & Renal clearance & & & \\
\hline Healthy & Renal clearance in healthy subjects & $0.0518(23.1 \%)$ & 0.0257 & 49.6 \\
\hline Dialysis patient & Renal clearance in dialysis patients & $4.32(861.3 \%)$ & 1.95 & 45.1 \\
\hline Vp2 (L) & Volume of distribution for unbound ACTZ & $0.382(68.2 \%)$ & 0.145 & 38.0 \\
\hline $\mathrm{Km}(\mathrm{mg} / \mathrm{L})$ & Maximal rate of transfer between compartments & $0.0916(31 \%)$ & 0.0438 & 47.8 \\
\hline \multicolumn{5}{|l|}{ Error } \\
\hline $\begin{array}{l}\text { Proportional error plasma } \\
\text { ACTZ }\end{array}$ & Proportional component of error model for plasma ACTZ & 0.0111 & 0.0023 & 20.3 \\
\hline $\begin{array}{l}\text { Additive error plasma } \\
\text { ACTZ }\end{array}$ & Additive component of error model for plasma ACTZ & 0.0203 & 0.0185 & 91.1 \\
\hline $\begin{array}{l}\text { Proportional error urine \& } \\
\text { dialysate ACTZ }\end{array}$ & Proportional component of error model for ACTZ in urine and dialysate & 0.152 & 0.040 & 26.0 \\
\hline \multicolumn{5}{|c|}{ Residual variability } \\
\hline Total ACTZ in plasma & & $10.5 \%$ & & \\
\hline
\end{tabular}




\begin{tabular}{lcc}
\hline Population Parameter & Parameter Description & Typical Value \\
\hline Unbound ACTZ in & RSE $\%$ \\
plasma & $11.7 \%$ \\
Total ACTZ in urine & $39.0 \%$ \\
Total ACTZ in dialysate & $39.0 \%$ \\
\hline
\end{tabular}

\section{Table 1b. Population PD Parameter Estimates}

\begin{tabular}{|c|c|c|c|c|}
\hline Population Parameter & Parameter Description & Typical Value & SE & RSE\% \\
\hline \multicolumn{5}{|l|}{ Population Mean } \\
\hline $\mathrm{IOP}_{\text {baseline }}(\mathrm{mm} \mathrm{Hg})$ & Baseline IOP & & & \\
\hline Healthy & Baseline IOP in healthy subjects & 12.4 & 0.4 & 2.8 \\
\hline Dialysis patient & Baseline IOP in dialysis patients & 15.5 & 1.6 & 10.4 \\
\hline $\operatorname{Emax}(\Delta \mathrm{IOP})(\mathrm{mm} \mathrm{Hg})$ & Maximal level of inhibition of IOP & & & \\
\hline Healthy & Maximal level of inhibition of IOP in healthy subjects & 7.4 & 2.8 & 38.3 \\
\hline Dialysis patient & Maximal level of inhibition of IOP in dialysis patients & 4.4 & 1.4 & 32.2 \\
\hline $\mathrm{IC}_{50}(\mathrm{mg} / \mathrm{L})$ & Concentration of unbound ACTZ associated with $50 \%$ of Emax & 2.47 & 1.27 & 51.4 \\
\hline \multicolumn{5}{|l|}{ Inter-subject variability } \\
\hline $\mathrm{IOP}_{\text {baseline }}(\mathrm{mm} \mathrm{Hg})$ & Baseline IOP & $0.0174(13.2 \%)$ & 0.0133 & 76.4 \\
\hline $\mathrm{IC}_{50}(\mathrm{mg} / \mathrm{L})$ & Concentration of unbound ACTZ associated with $50 \%$ of Emax & $1.38(173 \%)$ & 1.01 & 73.2 \\
\hline \multicolumn{5}{|c|}{ 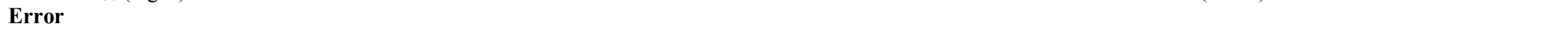 } \\
\hline Proportional error IOP & Proportional component of error model for IOP & 0.00968 & 0.0121 & 125.0 \\
\hline Additive error IOP & Additive component of error model for IOP & 2.97 & 1.61 & 54.2 \\
\hline \multicolumn{5}{|c|}{ Residual variability } \\
\hline IOP & & $17.0 \%$ & & \\
\hline
\end{tabular}

